\title{
Interannual variability in the tropical Indian Ocean: a two-year time-scale of Indian Ocean Dipole
}

\author{
Ming Feng ${ }^{\mathrm{a}, *}$, Gary Meyers ${ }^{\mathrm{b}}$ \\ ${ }^{\text {a } C S I R O ~ M a r i n e ~ R e s e a r c h, ~ U n d e r w o o d ~ A v e n u e, ~ F l o r e a t, ~ W A ~ 6014, ~ A u s t r a l i a ~}$ \\ ${ }^{\mathrm{b}}$ CSIRO Marine Research, Castray Esplanade, Hobart, Tasmania 7001, Australia
}

\begin{abstract}
The subsurface ocean dynamics of Indian Ocean Dipole (IOD) is identified using regular and extended empirical orthogonal function (EOF and EEOF) analyses of the TOPEX/Poseidon altimeter sea-level anomaly and expendable bathy-thermograph (XBT) temperature data. An IOD event is initiated by an anomalous upwelling along the SumatraJava coast at the start of the normal upwelling season in May-June. This enhances cooling of sea-surface temperature (SST) in the eastern Indian Ocean, which couples with a westward wind anomaly along the equator and drives rapid growth of IOD. The wind anomaly and associated Ekman pumping generate off-equatorial Rossby waves that travel westward, deepen the thermocline, and warm SST in the western Indian Ocean, causing the peak of an IOD event a few months after it begins. The decay of an IOD event is characterized by a slow eastward propagation of warm anomaly along the equator, with warm SST leading deepened thermocline depth. The deepened thermocline arrives at the eastern boundary and reduces the rate of cooling during the next upwelling season. This causes a positive SST anomaly in the eastern Indian Ocean in the following year of an IOD event. The evolution of the event during two upwelling seasons involves the SST, wind, and subsurface temperature. The vertical and horizontal subsurface thermal structure of IOD is described in detail. There are upward propagations of temperature anomaly from subsurface to surface layer in the XBT EEOF analysis, which implies the potential role of ocean dynamics on the SST. From correlation analyses, the subsurface evolution in the tropical Indian Ocean (indexed by the zonal equatorial wind) is strongly affected by Indian Ocean SST zonal gradient, and to a lesser extent by El Niño Southern Oscillation (ENSO). The observed behavior of the tropical Indian Ocean and the role of internal ocean dynamics suggest a coupled ocean/atmosphere instability, which may be initiated by ENSO or other anomalies during the early Sumatra-Java upwelling season; however, proof of its existence will require further research, including modelling and model-validation with these observations.
\end{abstract}

(C) 2003 Elsevier Science Ltd. All rights reserved.

\section{Introduction}

In recent years, there have been a growing number of studies on interannual variability in the tropical Indian Ocean (e.g., Perigaud and Delecluse, 1993; Masumoto and Meyers, 1998), with

\footnotetext{
*Corresponding author. Fax: + 61-8-9333-6555.

E-mail address: ming.feng@csiro.au (M. Feng).
}

increasing interest and description of Indian Ocean Dipole (IOD) events (Behera et al., 1999; Vinayachandran et al., 1999; Yu and Rienecker, 1999; Saji et al., 1999; Webster et al., 1999; Chambers et al., 1999; Xie et al., 2002). The early IOD studies focus on surface properties using wind and seasurface temperature (SST) data. An IOD event starts with anomalous SST cooling along the Sumatra-Java coast in the eastern Indian Ocean 
during May-June. The normal equatorial westerly winds during June-August weaken and reverse direction. And an IOD event peaks near September-October, with warmer than usual SST over large parts of the western basin (Saji et al., 1999). Vinayachandran et al. (2001) pointed out the existence of negative IOD events and Rao et al. (2002) provided a list of both positive and negative events since the 1870s. Some IOD events were coincident with strong El Niño Southern Oscillation (ENSO) events and some were not (Saji et al., 1999; Rao et al., 2002). Because there is nonnegligible correlation between ENSO and IOD indices (Nicholls and Drosdowsky, 2001), there is a vigorous scientific debate over whether or not IOD is in any way independent of ENSO.

An aspect of this debate that has not been fully addressed yet is the role of subsurface ocean structure in the tropical Indian Ocean. The time series of subsurface ocean data is relatively short; Nevertheless, some observations have emerged. Rao et al. (2002) and Saji (2001, pers. comm.) noted that a dipole is the dominant pattern of subsurface structure, while the dominant pattern of SST is different and is correlated to ENSO. They also presented evidence of Rossby wave propagation associated with IOD. Feng et al. (2001) identified that the first two empirical orthogonal functions (EOF) in the subsurface temperature along two expendable bathy-thermograph (XBT) sections delineate the peak and initiation/transition phases of the 1994 and 1997 IOD events. The two EOFs describe the same phenomena and are linked by off-equatorial Rossby waves and slow equatorial waves, as revealed from the satellite altimeter sea-level anomaly (SLA) data. Rao et al. (2002) detected similar ocean subsurface evolution in the tropical Indian Ocean from a numerical simulation. The present study intends to consolidate the above oceanographic analyses and early case studies with additional correlation and extended EOF (EEOF) analyses, and to provide a consistent picture of the subsurface ocean dynamics in IOD evolution. Although the present study cannot answer the question of whether or not IOD is independent of ENSO, it documents the horizontal, propagating features in the subsurface ocean during IOD and relates them to wind forcing and response. It also documents the potential role of subsurface temperature to influence SST, and it documents the vertical temperature structure in the poles of IOD in detail. We believe these horizontal and vertical transient features will have to be correctly modelled in future studies to fully understand the dynamics of IOD and its relationship to ENSO.

\section{Data}

The XBT upper-ocean temperature data are collected from a ship-of-opportunity network, which is operated by the Bureau of Meteorology, Australia, and CSIRO Marine Research (Meyers and Pigot, 1999). In the present study, two frequently repeated sections from the network in the tropical Indian Ocean are used: IX1 section from Fremantle, Australia, to Sunda Strait (between Sumatra and Java), Indonesia, and IX12 section from Fremantle to the Red Sea (Fig. 1). The XBT data are binned by latitude/depth and optimally averaged in time to bimonthly values (Meyers and Pigot, 1999). After subtracting the mean annual cycle, a 5-month moving average and then a five-point Hanning filter in time are applied to obtain the interannual temperature anomaly at each grid point. Anomaly fields from surface to $440 \mathrm{~m}$ during 1986-1999 are used in the study.

A 10 day $/ 0.25^{\circ}$ gridded altimeter SLA product based on the combined TOPEX Poseidon and ERS-1/ERS-2 missions from October 1992 to the end of 1999 was obtained from CLS Space Oceanography Division (Le Traon et al., 1998). A $1^{\circ}$ resolution subset of the data is used. Annual and semi-annual harmonics are calculated by linear regression and are subtracted from the data to obtain the interannual SLA. The data are further smoothed in time similar to the XBT data.

Other data used in the study include the monthly Southern Oscillation Index (SOI) obtained from the Bureau of Meteorology, Australia, SST data from 1981 to 1999 (Reynolds and Smith, 1994), and NCEP re-analysis wind stress data (Kalnay et al., 1996). The interannual anomalies of the data sets are computed with the same procedure as the XBT temperature. 

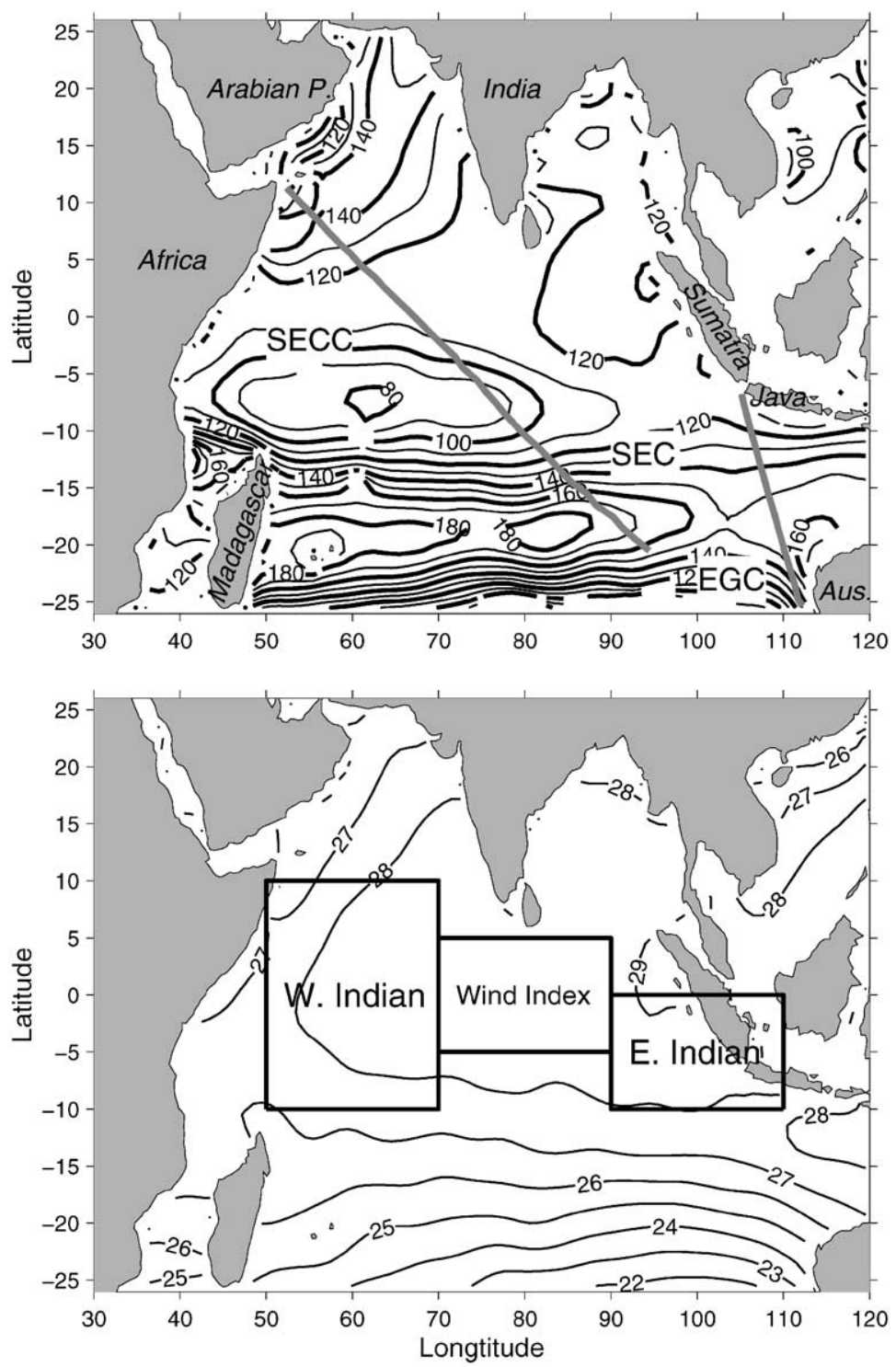

Fig. 1. Annual mean $20^{\circ} \mathrm{C}$ isotherm depth (upper panel) and SST (lower panel) from Levitus and Boyer (1994) climatology. The gray lines in the upper panel denote the IX1 (from Fremantle, Australia to Sumatra-Java coast) and IX12 (from Fremantle to Red Sea) repeated XBT sections. Note that stations south of $21^{\circ} \mathrm{S}$ along IX12 are not used in this study due to data dropouts. The solid boxes in the lower panel denote the regions used to define the westward wind stress index for the tropical Indian Ocean (averaged over $5^{\circ} \mathrm{S}-5^{\circ} \mathrm{N}$, $70-90^{\circ} \mathrm{E}$ ), and western (averaged over $10^{\circ} \mathrm{S}-10^{\circ} \mathrm{N}, 50-70^{\circ} \mathrm{E}$ ) and eastern (averaged over equator-10 $\mathrm{S}, 90-100^{\circ} \mathrm{E}$ ) tropical Indian Ocean SST anomalies.

\section{Mean state and interannual anomaly indices}

The tropical Indian Ocean can be regarded as an extension of the Pacific warm pool, with SST above $28^{\circ} \mathrm{C}$ (Fig. 1). Unlike the Pacific Ocean, the eastern equatorial Indian Ocean does not have a cold tongue: SST is slightly warmer and the $20^{\circ} \mathrm{C}$ isothermal depth is deeper in the east than the west, and the annual mean wind stress over the equator is directed toward the east due to the 
existence of the atmospheric convection surrounding the Indonesian Seas.

The annual mean depth of the $20^{\circ} \mathrm{C}$ isotherm portrays the surface-layer circulation pattern in the off-equatorial region (Fig. 1, upper panel). There is a pronounced zonal ridge along $7^{\circ} \mathrm{S}$ west of $90^{\circ} \mathrm{E}$, geostrophically balancing the westwardflowing South Equatorial Current (SEC) to its south and the South Equatorial Countercurrent (SECC) to its north (Donguy and Meyers, 1995). The Indonesian Throughflow joins the SEC from gaps between the Indonesian Archipelago and Australia. The thermocline trough along $20^{\circ} \mathrm{S}$ separates the SEC from the eastward flowing East Gyral Current (EGC), which mostly feeds the Leeuwin Current along the west coast of Australia. North of the equator, the annual mean circulation is weaker because of annual reversal of the monsoon winds. Salient features are the northeastward East Arabian Coastal Current/Somali Current and the return flows in the Arabian Sea (Schott and McCreary, 2001).

The IX1 section intersects the Indonesian Throughflow/SEC system and is influenced by the equatorial Indian Ocean at its northern end, and by Pacific signals at its southern end, through the equatorial and coastal wave guides (Clarke and Liu, 1994; Meyers, 1996). The IX12 section traverses the SEC/SECC ridge south of the equator, crosses the equatorial wave-guide and the boundary current at the African coast. This XBT section is influenced by strong annual/ interannual Rossby waves south of the equator (Masumoto and Meyers, 1998).

Interannual variability of surface properties in the tropical Indian Ocean is characterized in this study by indices calculated from SST and wind data (Fig. 2). Because the focus is on the upperocean evolution, we use westward zonal wind stress anomaly along equator averaged over 70 $90^{\circ} \mathrm{E}, 5^{\circ} \mathrm{S}-5^{\circ} \mathrm{N}$ (Fig. 1) as an index for tropical Indian Ocean interannual variability. Chambers et al. (1999) defined a similar wind index averaged over $80-100^{\circ}$ E. Following Saji et al. (1999), the western and eastern tropical Indian Ocean SST anomalies are indexed with averages within 50 $70^{\circ} \mathrm{E}, 10^{\circ} \mathrm{S}-10^{\circ} \mathrm{N}$ and $90-110^{\circ} \mathrm{E}, 10^{\circ} \mathrm{S}$-equator, respectively (Fig. 1).

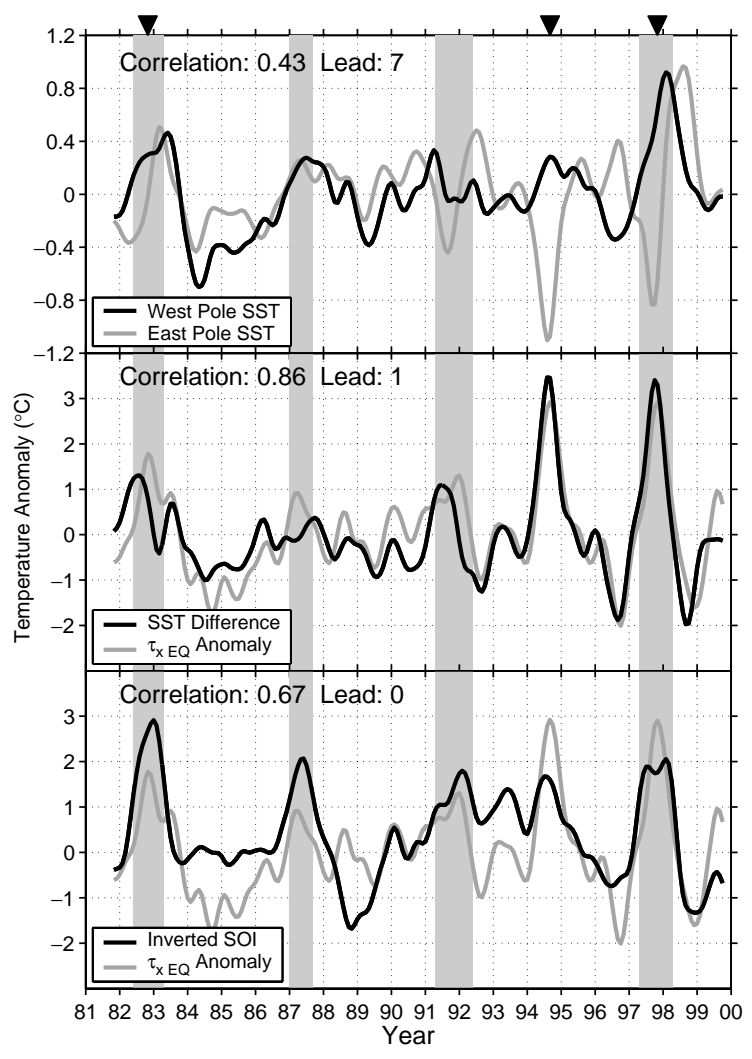

Fig. 2. Time series of (upper panel) interannual SST anomalies in the western and eastern tropical Indian Ocean, (middle panel) SST difference between western and eastern tropical Indian Ocean and equatorial Indian Ocean westward wind stress anomaly and (lower panel) inverted SOI and the westward wind stress anomaly. The SST difference, wind anomaly, and inverted SOI are normalized with their standard deviations. At top left of each panel we calculated the maximum correlation between the two variables in the panel and the leading time in months of the maximum correlation (first variable leads the second). The vertical gray shadings denote the recognized El Niño events, and the inverted triangles in the upper panel denote the peaks of the IOD events.

Variability of the surface indices is briefly described here to set the scene for the subsurface analyses. A distinctive feature of the IOD events, such as 1982, 1994, and 1997, is a variation in the eastern Indian Ocean SST that evolves over a period of 2 years: Cold SST anomaly first develops during the upwelling season in the middle of the year while the western Indian Ocean warms, then warm SST anomaly in the east occurs during the next upwelling season about 7 months after the 


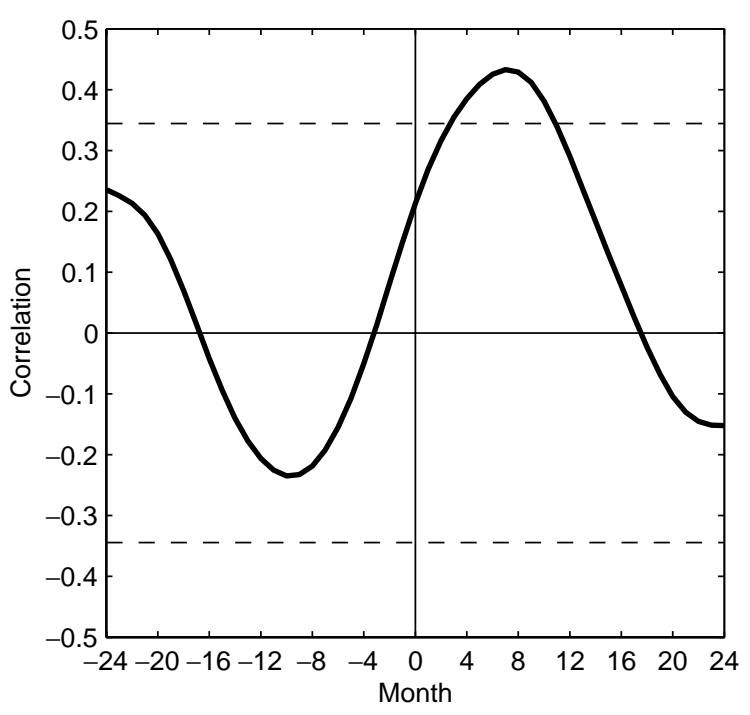

Fig. 3. Lag correlation between the western and eastern Indian Ocean SSTs (positive lags denote west leading east). The dashed lines denote correlations above $95 \%$ significance level for a 30 degree of freedom calculated from auto-correlation coefficients.

peak western Indian Ocean warming (Fig. 2a). We call this feature of IOD a two-year time-scale, and note that it may be related to biennial oscillation described by Meehl (1993) and Meehl and Arblaster (2002). Due to spatial/temporal evolution of the two-year time-scale, the SSTs in the west and east are nearly in quadrature phase during IOD evolution, although the warm SST anomalies in the west have different magnitudes during different IOD events (Fig. 2a). Note that the positive SST anomaly in the west leads that in the east by 7 months, with a positive correlation of 0.43 (Fig. 3). The interannual SST difference across the tropical Indian Ocean leads the wind index by 1 month, with a high correlation of 0.86 (Fig. 2b). These indices and their relationship to SOI will be discussed further in Section 7, after describing the role of subsurface dynamics in IOD variations.

\section{Upper-ocean interannual variability}

The two-year variation of SST in the eastern Indian Ocean from a minimum to a maximum during adjacent upwelling seasons, and the quadrature phase relationship between the eastern and western Indian Ocean SSTs is interpreted here in relation to subsurface thermal structure. It was already shown that the zonal wind anomaly along the equator, which drives the upper-ocean response, is closely related to the Indian Ocean SST difference. The surface features suggest a systematic evolution on time scales that are typical of Indian Ocean circulation and subsurface dynamics. The role of ocean dynamics is documented in this and the following sections using SLA and XBT data.

The standard deviation of SLA is high in two regions: within the SEC/SECC ridge in the west, and near the coast of Sumatra-Java in the east, both having peak magnitudes of $8-9 \mathrm{~cm}$ (Fig. 4). Note that the time period of the SLA data embraces the 1994 and 1997 IOD events. SLA is inversely proportional to the thermocline depth in most tropical oceans: a high SLA represents a deepened thermocline depth, and vice versa. The two XBT sections intersect these two high activity areas, that is, they capture similar upper-ocean variability as the SLA data. High variability also occurs in the Somali Current region, likely influenced by the Great Whirl and its variability (Schott et al., 1997), and along the coast of Bay of Bengal, likely influenced by coastal Kelvin wave activity.

The mean subsurface temperature structure on the XBT lines and their standard deviation is shown in Figs. 5 and 6. The SEC is denoted by the downward slope of thermocline from $10^{\circ}$ to $15^{\circ} \mathrm{S}$ in the mean subsurface structures along both XBT sections (Figs. 5 and 6, upper panels). The slope is stronger in the west along IX12, consistent with the increasing SEC transport (Donguy and Meyers, 1995). Further south, the upward slope of isotherms in the upper $150 \mathrm{~m}$ supports the EGC. The thermocline in the SEC/SECC ridge along IX12 is shallow and tight, and slightly deepens toward the equator. The thermocline becomes spread and elevated near the African coast, supporting a mean northward current, which forms the lower limb of a shallow overturning cell in the tropical Indian Ocean (Godfrey et al., pers. comm.). 


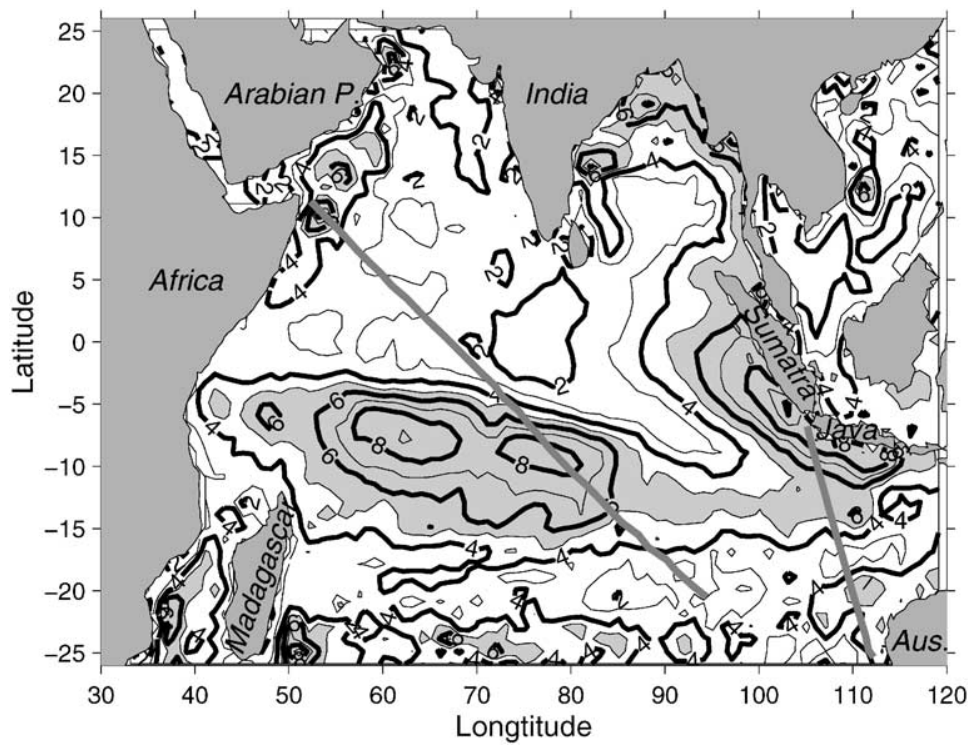

Fig. 4. Standard deviations of SLA in the tropical Indian Ocean. The unit is $\mathrm{cm}$ and the shaded areas are with standard deviations larger than $5 \mathrm{~cm}$. The locations of the two XBT sections are shown.

The high variability sectors along the XBT sections are consistent with the high variability in SLA, with strongest variability near the SumatraJava coast along IX1 (maximum above $2^{\circ} \mathrm{C}$ ), near the SEC/SECC ridge (maximum above $1.75^{\circ} \mathrm{C}$ ), and near the African coast (Figs. 5 and 6, lower panels). The highest variability is close to the depth of the $20^{\circ} \mathrm{C}$ isotherm where the vertical temperature gradient is largest.

The interannual temperature variations within the two high variability regions $\left(6.78^{\circ} \mathrm{S}, 105.17^{\circ} \mathrm{E}\right.$ near the Sumatra-Java coast at the northern end of IX1 and $8.48^{\circ} \mathrm{S}, 77.64^{\circ} \mathrm{E}$ in the SEC/SECC ridge along IX12) show the relationship between surface and subsurface temperature (Figs. 7 and 8 ). These locations are near the poles of IOD.

The subsurface thermal variability near the Sumatra-Java coast shows a complex mix of time scales ranging from months to years (Fig. 7). The upper panel of Fig. 7 displays the optimal interpolated temperature time series near the Sumatra-Java coast. The surface isothermal layer depth is about $50 \mathrm{~m}$, and the surface-layer temperature exhibits a regular annual cycle during most years, with peak temperature of more than $29^{\circ} \mathrm{C}$ in February-March. In the thermocline, there exists intensive semi-annual variability, which is remotely driven by the equatorial Indian Ocean semi-annual Wyrtki jet (Clarke and Liu, 1993). Superimposed on the semi-annual cycle, there is an annual component driven by local monsoon winds, with upwelling favorable southeasterly wind for 6 months from April to September, and downwelling favorable wind during the other 6 months (Clarke and Liu, 1993). The combination of the remote and local forcing causes stronger upwelling during the July-September season. Intensified upwelling events develop near the Sumatra-Java coast during the upwelling seasons of 1994 and 1997 (Fig. 7, upper panel). The thermocline is lifted to very shallow depths and very low SST was observed. Moderate upwelling events occur during 1987 and 1991. The two strong upwelling events also are revealed in the interannual temperature anomaly field (Fig. 7, lower panel). The evolution of temperature anomaly has a 2-year time-scale, with cold anomaly during 1994 and 1997 followed by warm anomaly during 1995/96 and 1998 .

Near the SEC/SECC ridge, both the surface isothermal layer temperature and thermocline depth reveals dominant annual cycles (Fig. 8, 


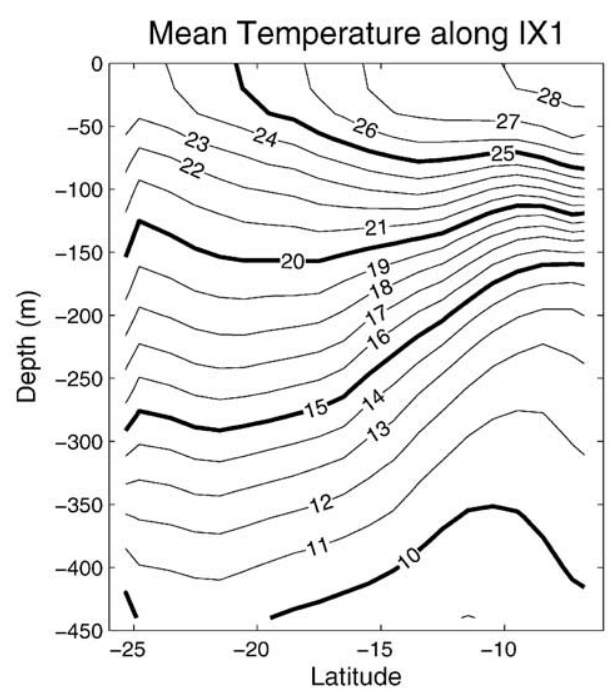

Interannual Standard Deviation
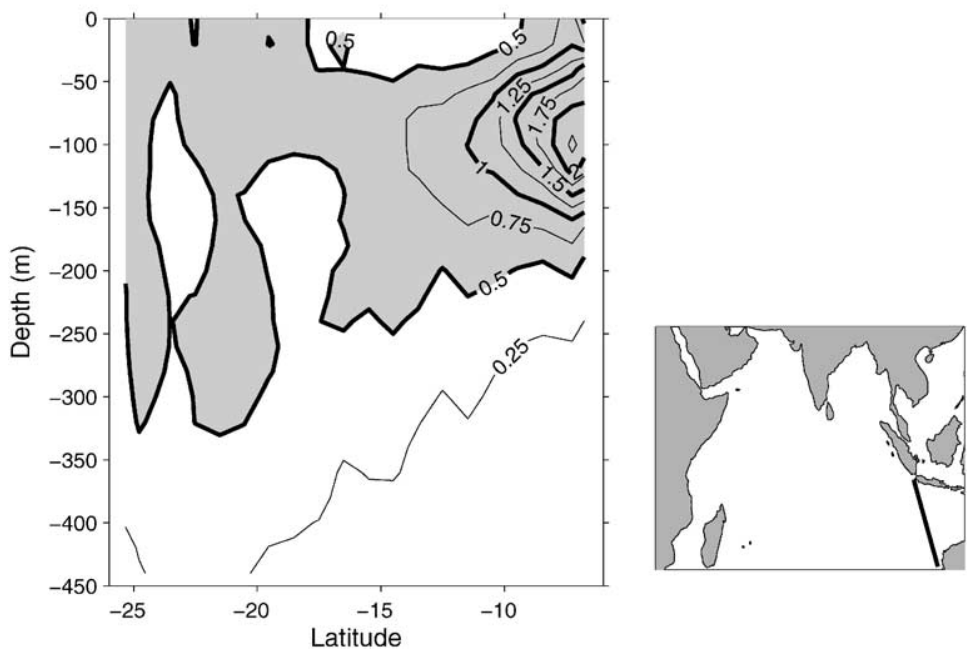

Fig. 5. (Upper panel) Annual mean temperature structure and (lower panel) interannual temperature standard deviations in the upper $440 \mathrm{~m}$ along the IX1 XBT section. The shaded areas in the lower panel denote standard deviations larger than $0.5^{\circ} \mathrm{C}$. The inset shows the location of the XBT section.

upper panel). The thermocline is deepest near the end of the calendar year, due to combined effect of local Ekman pumping and westward propagating Rossby waves generated in the central Indian Ocean (Masumoto and Meyers, 1998). SST reaches its peak value about 2-3 months later, driven primarily by local air-sea fluxes. A deepened thermocline, which turns off the entrainment mixing at the base of the mixed layer, may also contribute. The interannual anomaly near the SEC/SECC ridge tends to be a mirror image of that near the SumatraJava coast, with deepened thermocline during 1991, 1994, and 1997, and elevated thermocline during the following years in 1992, 1995 and 1998 (Fig. 8, lower panel). Note that there is no similar variability associated with the $1986 / 87 \mathrm{El}$ Niño. 

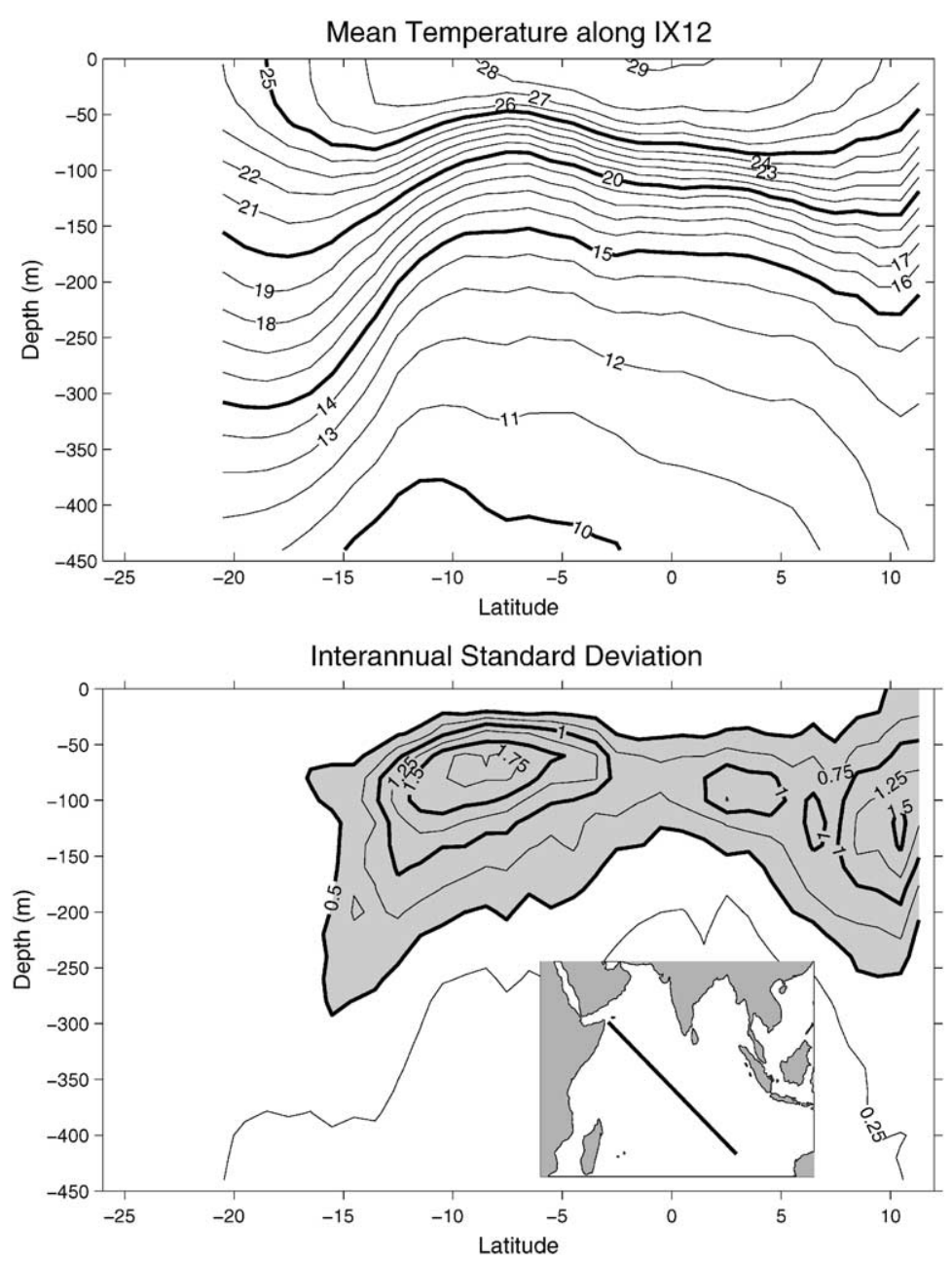

Fig. 6. Same as Fig. 5 except for the IX12 XBT section.

\section{EOF analysis}

The EOF analysis is based on SLA data covering the two IOD events (1994 and 1997) and XBT data extending the time series back in time to the 1986/87 El Niño. The EOF analysis demonstrates the tropical Indian Ocean variations that occurred during two El Niño's (1986/87 and 1997/98) and the unusual long El Niño-like period during the early 1990s. The EOF analyses are calculated independently for the SLA and XBT data sets. Before performing the EOF analysis, we normalize the interannual anomaly field at each grid point. After the EOF analysis, the interannual standard deviation at each grid point is multiplied back to recover the unit in the loading field. Also we normalize the time coefficients with their standard deviation so that the amplitude in the EOF loading should be interpreted to correspond to one standard deviation of the time coefficients. For SLA, mode 1 explains $38 \%$ of the variance and mode $213 \%$, while for the XBT data mode 1 explains $19 \%$ of the variance, and mode $212 \%$.

The first two EOF modes from SLA and XBT capture the dominant interannual variability structure in the tropical Indian Ocean. The SLA EOF-1 exhibits a dominant east-west dipole (Fig. 9), consistent with Chambers et al. (1999) 

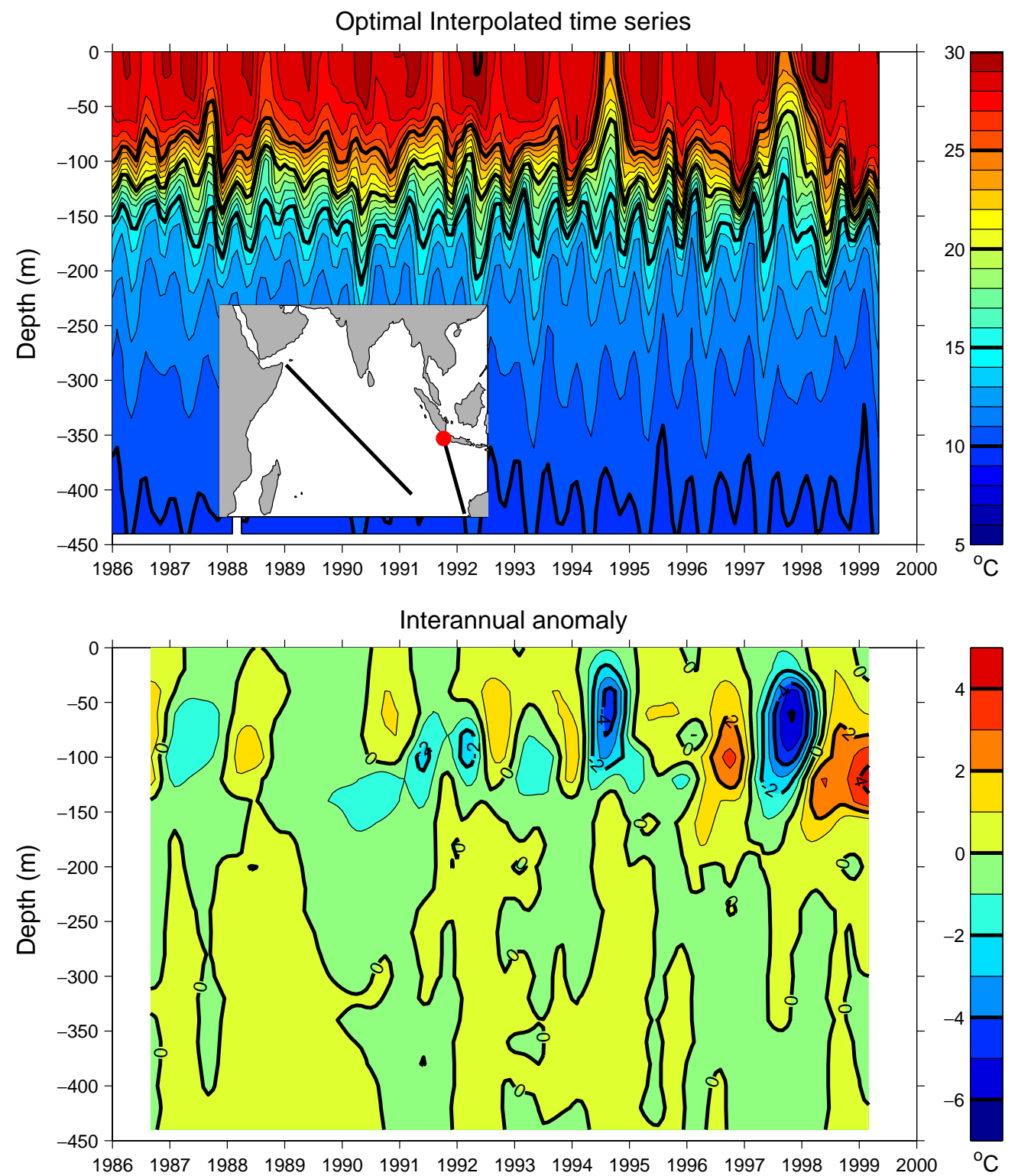

Fig. 7. : Time series of (upper panel) optimal interpolated temperature and (lower panel) interannual temperature anomaly profiles at $6.78^{\circ} \mathrm{S}, 105.17^{\circ} \mathrm{E}$, the northern end of IX1. The station position is marked as a red dot in the inset of the upper panel. The missing data in the deep layers are filled by linear interpolation when calculating the anomaly field.

and Rao et al. (2002). Negative SLA (shallow thermocline) appears in the eastern Indian Ocean with peak values of about $6 \mathrm{~cm}$ along the Sumatra-Java coast, extending northward into Bay of Bengal and southward to northwest Australia, likely along the coastal wave guides.
The western Indian Ocean has dominantly positive anomaly (deep thermocline), with peak values of more than $6 \mathrm{~cm}$ at the $\mathrm{SEC} / \mathrm{SECC}$ ridge. $\mathrm{EOF}-1$ from the XBT analysis is consistent with the SLA EOF-1 (Fig. 9, lower panels). Along IX1, EOF-1 is mostly negative, with peak value of $-1.2^{\circ} \mathrm{C}$ near 

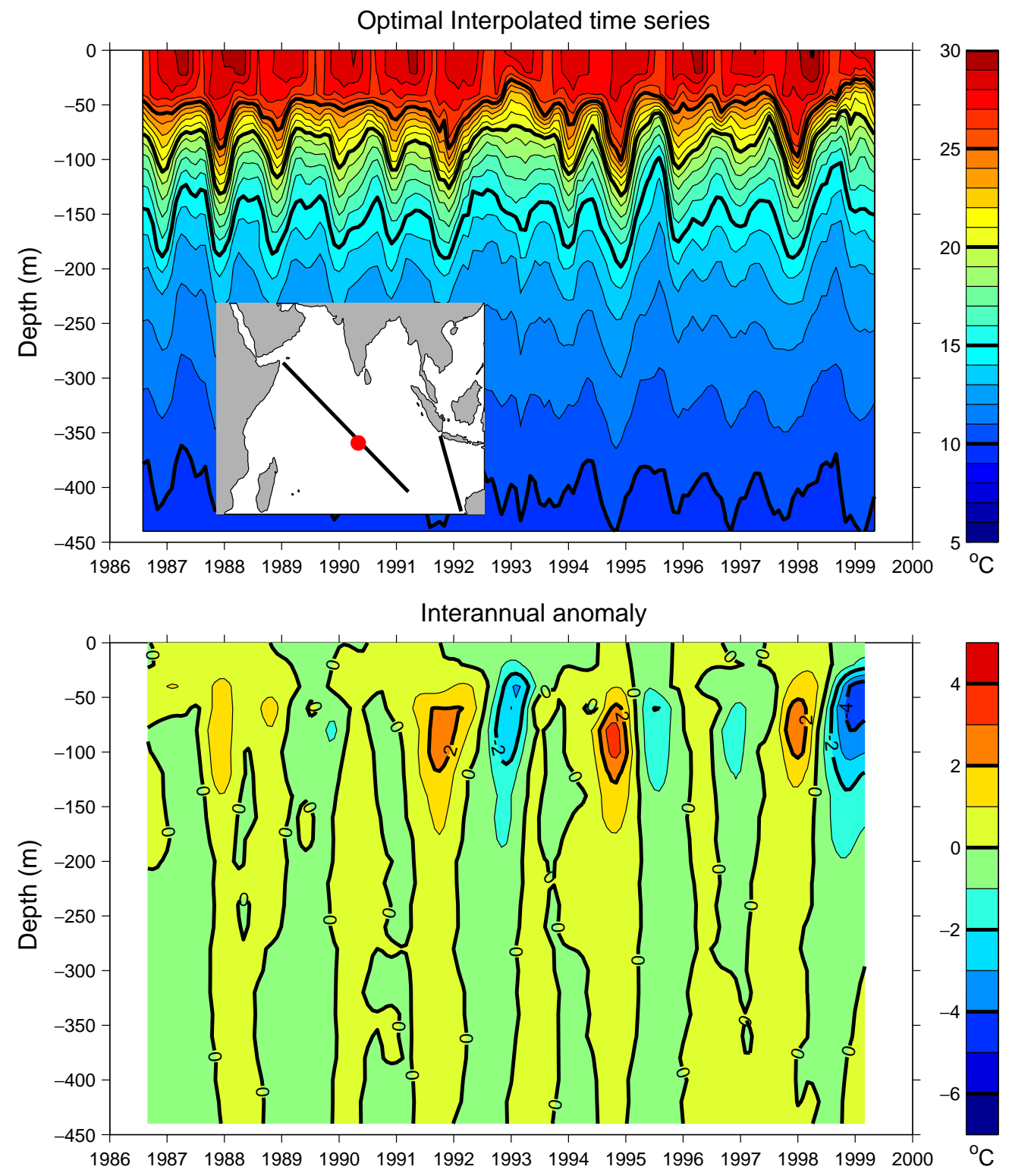

Fig. 8. Same as Fig. 7 except for $8.48^{\circ} \mathrm{S}, 77.64^{\circ} \mathrm{E}$ at the SEC/SECC ridge along IX12.

the Sumatra-Java coast. And along IX12, EOF-1 is dominantly positive with peak value of $1^{\circ} \mathrm{C}$ near $6-12^{\circ} \mathrm{S}$ at the SEC/SECC ridge. EOF-1 for SLA and $\mathrm{XBT}$ represent the peak phase of an IOD event.

Mode 2 EOF loading (EOF-2) of SLA has negative loading confined to the Sumatra-Java coast, and positive loading centered near $13^{\circ} \mathrm{S}$, $95^{\circ} \mathrm{E}$ that extends in the northwest-southeast direction (Fig. 10, upper panel). There are weaker counterparts in the northern Indian Ocean. Other noticed features are negative loading northeast of Madagascar and near the African coast around $10^{\circ} \mathrm{N}$, which are due to delayed influences of 


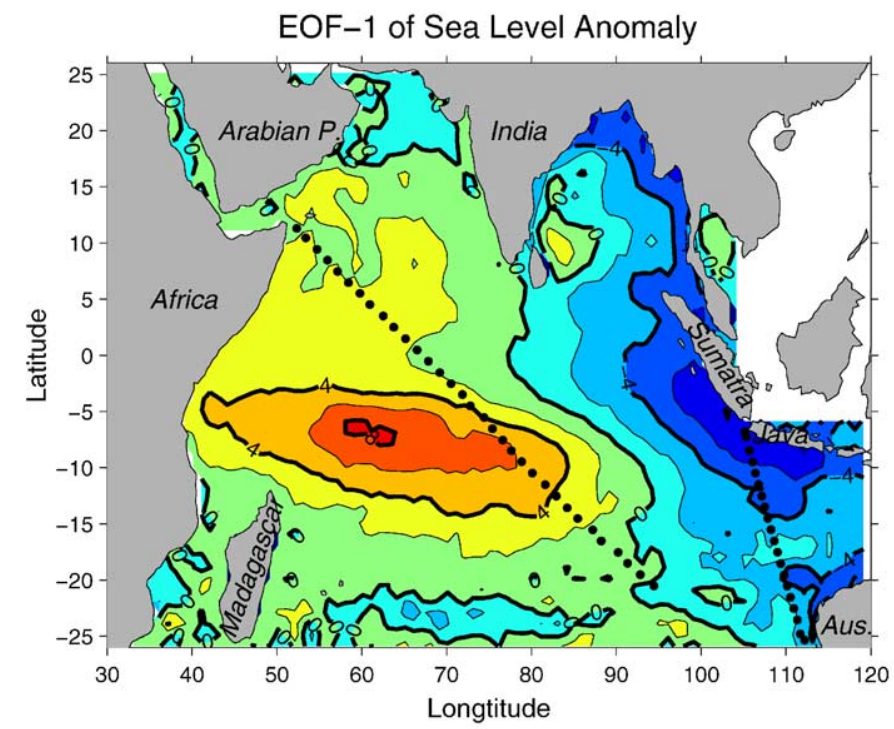

Joint EOF-1 of XBT Temperature
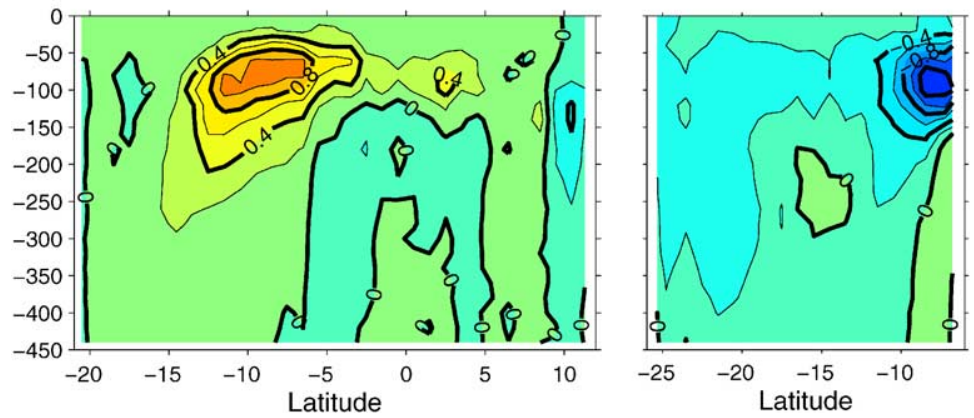

Fig. 9. EOF-1 loadings for SLA (top panel), and temperature anomaly along the two XBT sections (lower panel: right, IX1; left, IX12). The unit for SLA loading is $\mathrm{cm}$ and the contour interval is $2 \mathrm{~cm}$. The unit for temperature loading is ${ }^{\circ} \mathrm{C}$ and the contour interval is $0.1^{\circ} \mathrm{C}$. The locations of the XBT sections are denoted with black dots in the upper panel.

slower Rossby waves at higher latitudes as shown later in the extended EOF results. EOF-2 loading for the XBT data follows SLA EOF-2 closely, with IX1 intersecting the negative pole along SumatraJava and the eastern end of the positive pole near $14^{\circ} \mathrm{S}$, and IX12 intersecting the western side of the positive pole and the negative anomaly near the African coast (Fig. 10, lower panels). The negative temperature loading along the Sumatra-Java coast has a surface signature and extends offshore within the surface layer. The positive temperature anomalies along IX1 and IX12 occur in the subsurface, though the total effect of mixed layer cooling and subsurface warming causes the positive dynamic height anomaly, as indicated in the SLA EOF-2 loading. The XBT analysis indicates that the heave of the thermocline affects SST primarily in the region offshore from Sumatra-Java. The effect extends about $500 \mathrm{~km}$ offshore from Java, and farther offshore close to the equator.

The EOF time coefficients of the SLA and XBT data largely follow each other from 1994 to 1998 (Fig. 11). The EOF-1 evolution contains response to an ENSO teleconnection represented by the inverted SOI (Fig. 11a), as described by Chambers et al. (1999). Nevertheless, the EOF-1 evolution and SOI are different in some details. The inverted SOI peaks at about the same level in 1987, 1991/ 


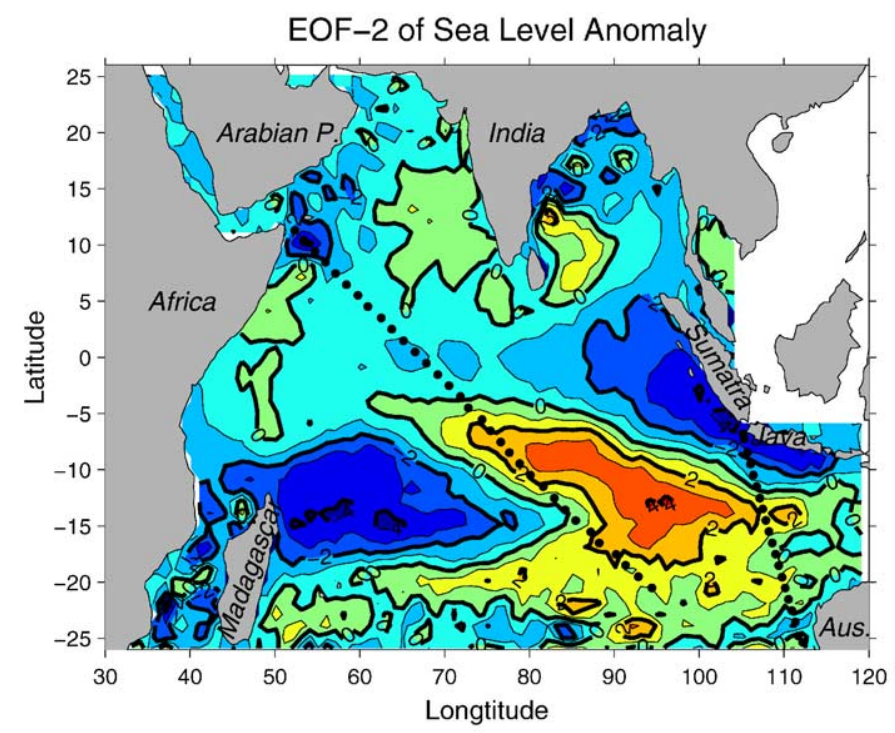

Joint EOF-2 of XBT Temperature
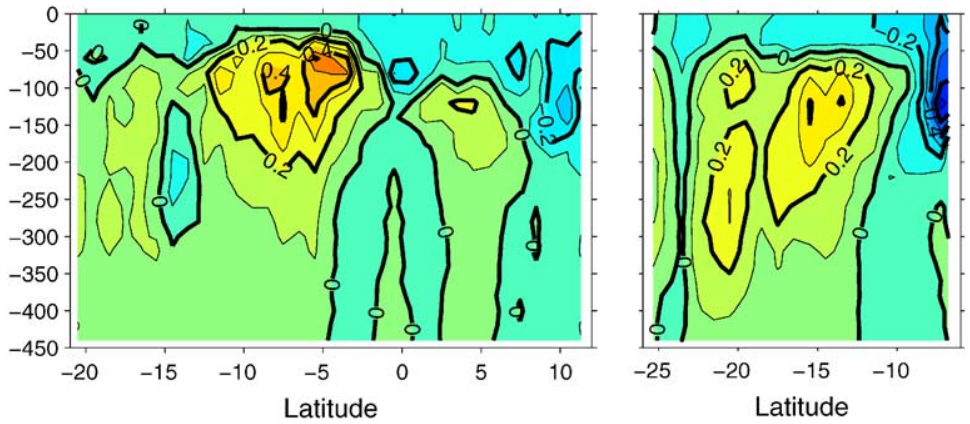

Fig. 10. Same as Fig. 9 except for EOF-2 loading.

92, 1994, and 1997/98 while the Indian Ocean EOFs for SLA and XBT have very different peak heights during these time periods. There are weak anomalies during the 1986/87 El Niño and a transition from a negative peak (1992) to a positive peak (1994) during the extended 1991-94 El Niño. During the 1994 and 1997 IOD, the EOF-1 time coefficients (Fig. 11a) lag the wind index by 1-2 months (Fig. 11b).

The time coefficients of EOF-2 from the XBT data only have large magnitudes related to the 1994 and 1997 IOD events, with positive coefficients leading the peaks of IOD development in EOF-1 and negative coefficients lagging the peaks.
That is, upwelling along Sumatra-Java and downwelling off the coast, in July-August 1994 and 1997, lead the peak IOD events in EOF-1, while downwelling along Sumatra-Java coast and upwelling off the coast, in May 1995 and June-July 1998, lag the peak IOD by 6-9 months. Following Lau and Wu (1999), Feng et al. (2001) calculated spatial correlation between the observed temperature anomaly and EOF-reconstructed temperature anomaly fields and revealed that EOF-2 was unique to IOD.

The lead-lag relationships suggest that a spatial/ temporal evolution is at least partially represented by the two EOF modes during an IOD event. Note 

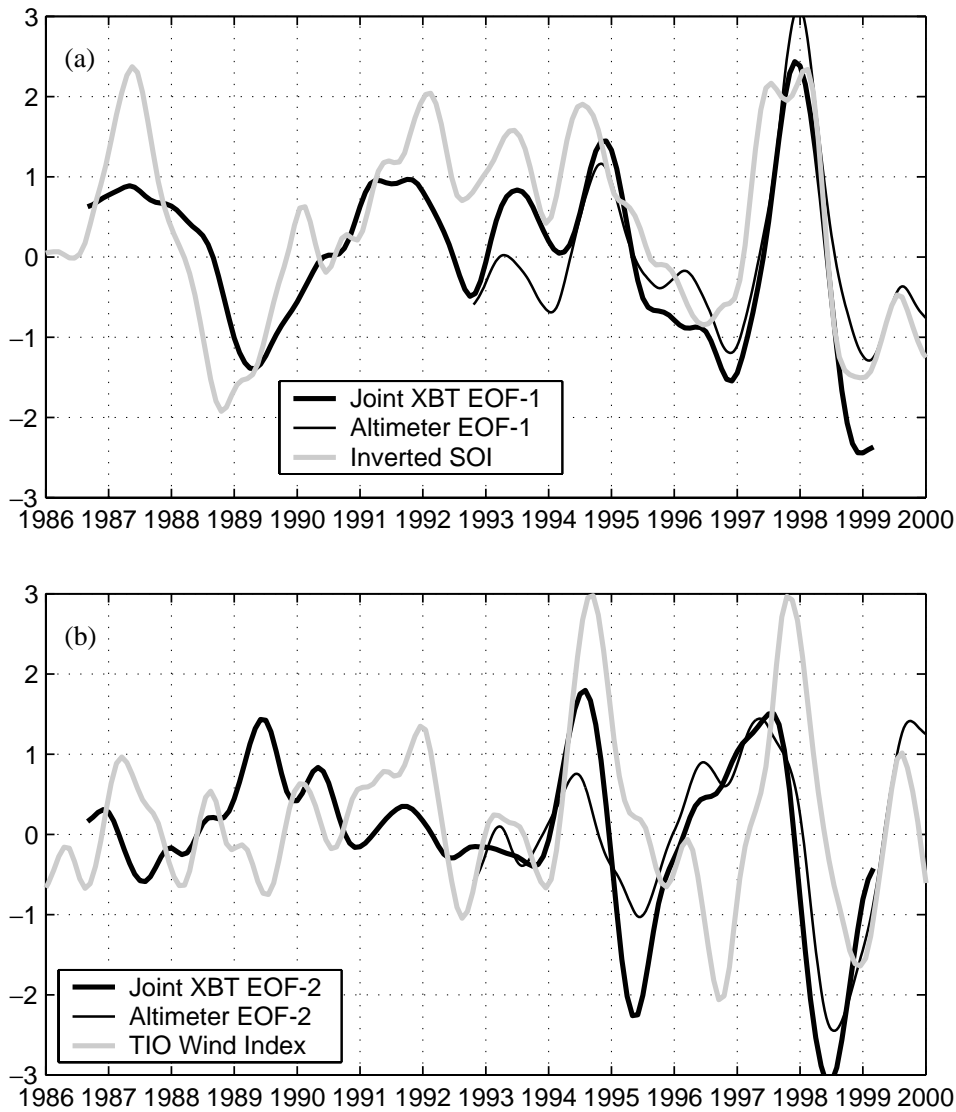

Fig. 11. (a) Time coefficients of the XBT EOF-1 and SLA EOF-1, and inverted SOI, and (b) time coefficients of the XBT EOF-2 and SLA EOF-2, and the wind index.

that the overall amplitudes of EOF-1 are larger than EOF-2, so EOF-1 is not simply due to free wave propagation from EOF-2, but with amplification. The Rossby waves forced by Ekman pumping in the southern tropical Indian Ocean may be important (Masumoto and Meyers, 1998). In section 6, we use EEOF and correlation analyses to examine the spatial/temporal evolution related to IOD and the potential role of the upperocean response to affect SST.

The third and fourth EOFs (not presented) for both XBT and SLA accounted for $6 \%$ to $8 \%$ of variance. There is no similarity between the higher modes of XBT and SLA EOFs in terms of both spatial structure and temporal evolution. Thus, the higher modes more likely represent localized phenomena, not basin scale variability, so that they are not presented here. Similarly, higher modes are not considered in the later EEOF analysis.

\section{Extended EOF and correlation analyses}

A modal-transition is indicated in the standard EOF analysis, that is, EOF-2 (Fig. 11b) leads EOF-1 (Fig. 11a) as the Sumatra-Java region cools (Figs. 9 and 10), then EOF-1 leads the negative phase of EOF-2 by $6-9$ months as the western Indian Ocean warms (Fig. 11b) in 1995 and 1998. To document the modal-transition further, we perform additional EEOF (Lau and Chan, 1985) and correlation analyses in this section. Note that in the EEOF analysis, the data 

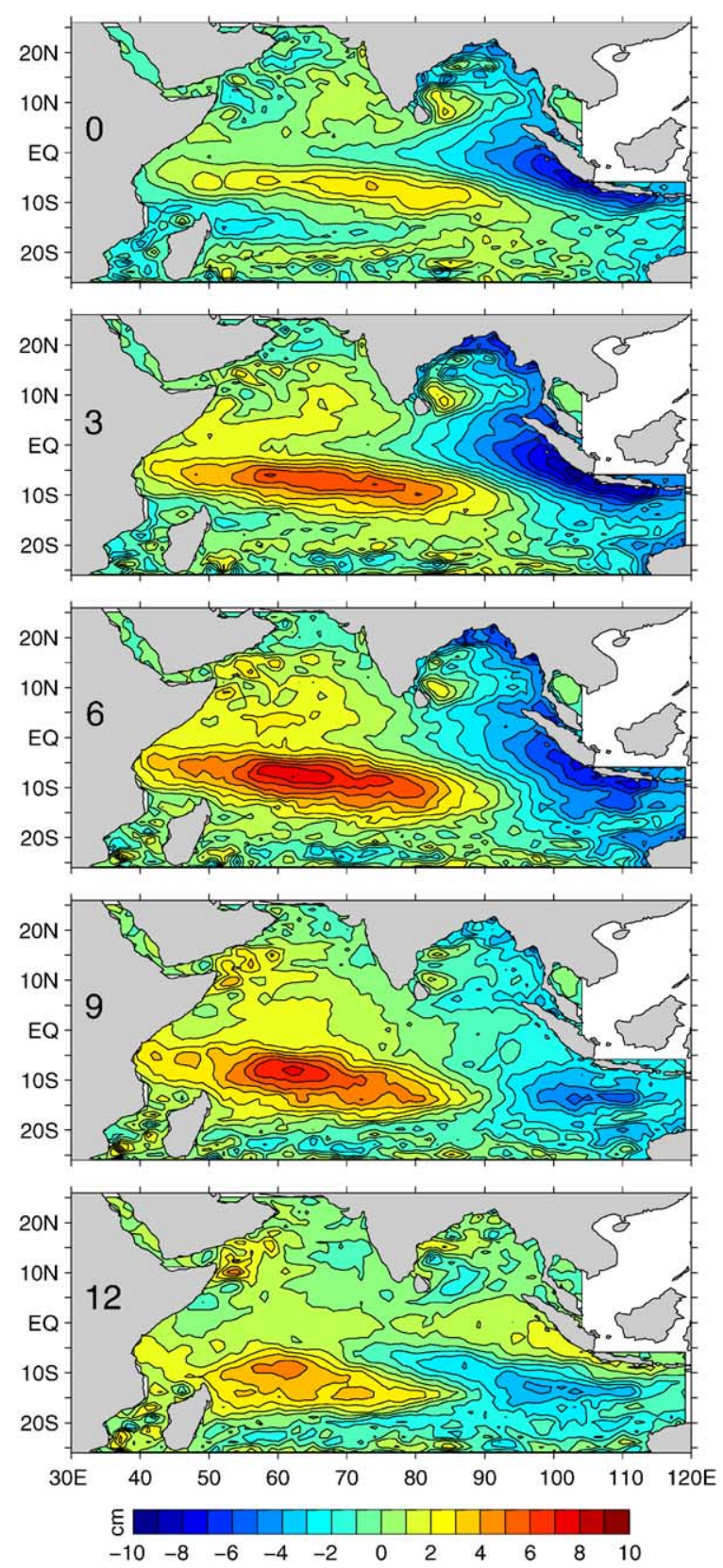

Fig. 12. Loading sequence of the SLA EEOF-1. The lags are every 3 months, as denoted in the African landmass. The unit is $\mathrm{cm}$ and the contour interval is $1 \mathrm{~cm}$. Red area denotes positive anomaly and blue for negative anomaly.

are not normalized. The EEOF for the SLA and XBT data are calculated with four 3-month lagging units. Like in the regular EOF analysis, the time coefficients of EEOFs are normalized. Because of the quadrature phase difference between the first two extended modes, we only present results from SLA EEOF-1 (Figs. 12 and 13).

The time coefficients for SLA EEOF-1 (Fig. 13) indicate the phase of the zero-lag spatial pattern (Fig. 12), and the lag patterns show the spatial/ temporal evolution after lag zero. The EEOF zerolag pattern is similar to the regular EOF-2, indicating the start of an IOD event in the Sumatra-Java upwelling season. The 3-month lag pattern is approaching the peak of an IOD event, with east/west SLA contrast similar to regular SLA EOF-1. A forced Rossby wave (Masumoto and Meyers, 1998) is generated in the centralwestern region. The amplification of the propagating signals is also obvious, implying positive convolution with wind forcing. At 6-month lag, the negative anomaly in the eastern Indian Ocean moves off the equator and the positive anomaly in the west starts to reflect and travel eastward along the equator. The eastward propagation along the equator reaches the eastern boundary at the 9- and 12-month lags, much slower than a free equatorial Kelvin wave. In the mean time, the negative anomalies along the Sumatra-Java coast travel westward, mostly south of the equator. The 12month lag loading resembles reversed regular EOF-2. Thus, the EEOF analysis suggests that the lead-lag relation between the two regular EOF modes are linked by the off-equatorial Rossby wave and slow eastward equatorial wave, as well as their reflection at the east/west boundaries.

To demonstrate the modal-transition further, the propagation patterns in EEOF are reproduced by lagged correlation between SLA and the wind index. Six correlation snapshots from 3-month lead to 12-month lag are shown in Fig. 14. On average, correlation higher than 0.6 is significant at $95 \%$ level. The reproduced features are the initiation correlation structure at 3-month lead, the expansion of negative correlation in the eastern Indian Ocean with time, the intensification and westward propagation of the positive correlation, and the west/east contrasting correlation structure during zero to 3-month lag. The east pole peaks at zero-lag and the west pole peaks at 3-month lag. 


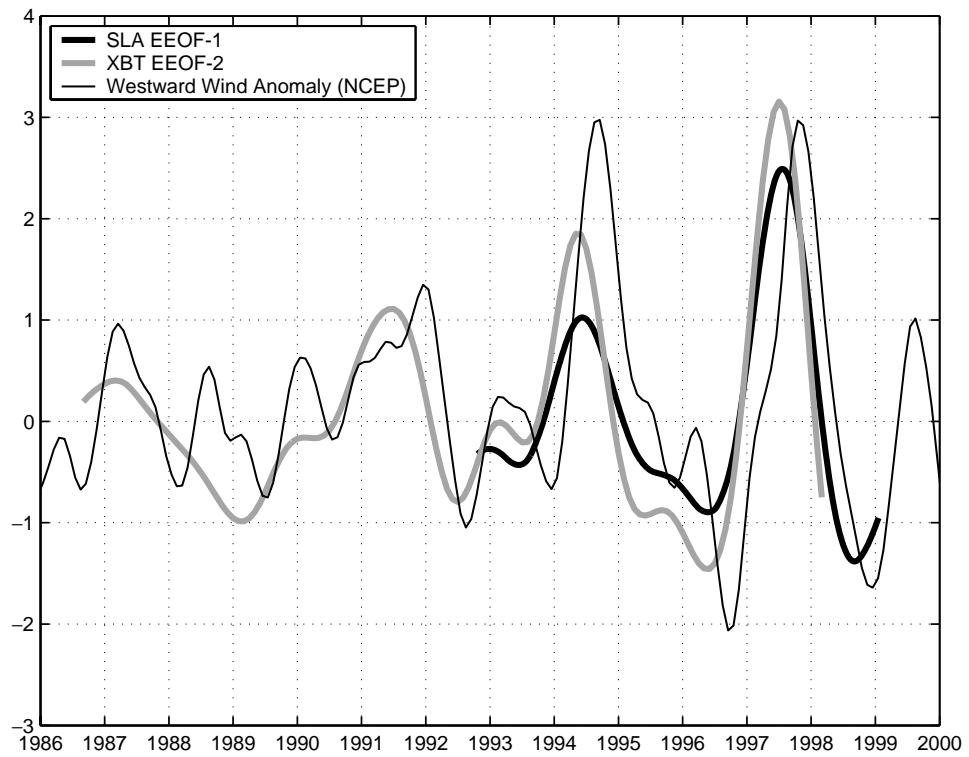

Fig. 13. Time coefficients of the SLA EEOF-1, XBT EEOF-2, and the wind index.

And at zero-lag, the correlation is generally higher than 0.9 near the Sumatra-Java coast. Also reproduced is the slow eastward propagation along the equator from 3- to 12-month lag, and a correlation pattern similar to the negative EOF-2 is formed at 12-month lag.

Lagged correlations between SST and wind index during 1992-1999 show a monopole negative correlation structure along the Sumatra-Java coast at 3-month lead (Fig. 15). This is consistent with the regular XBT EOF analysis that the EOF2 positive pole only has subsurface temperature signals. Positive correlation appears in the western Indian Ocean at zero-lag when the negative correlation in the east starts to decay. Unlike SLA, SST correlation near the eastern boundary does not expand in the north-south direction. There also exists eastward propagating positive SST correlation along the equator during the demise of the events, leading the eastward propagation of SLA correlation, in the 6- and 9month lag snapshots (Figs. 14 and 15). This seems to be a demonstration of air-sea coupling.

The XBT EEOFs also depict the linkage between the first two ordinary EOF modes. In addition, they identify the potential role of subsurface ocean dynamics in affecting SST. Here we only present the EEOF-2 due to its similar phase relationship with SLA EEOF-1 (Fig. 13). The zero-lag loading of XBT EEOF-2 is close to regular EOF-2, the initiation mode, with cooling near Sumatra-Java coast and subsurface warming in the SEC along IX1, and warming south and north of the equator along IX12 (Feng and Meyers, 2001), and the 3-month lag loading of EEOF-2 is close to the peak of an IOD event (Fig. 16). Both the cooling along IX1 and warming along IX12 intensify with time, peaking at 3- and 6-month lags, respectively. At the 9-12-month lag, the subsurface positive anomalies along the Sumatra-Java coast extend upward with time and then offshore to affect SST. The subsurface negative temperature anomalies in the SEC/SECC ridge along IX12 also expand upward to the surface at 12-month lag. These upward propagation signals may indicate the influence of ocean dynamics on the mixed layer heat budget, which assist to cool down SST in the east and warm up SST in the west during the IOD development, and have reversed effects during the demise of IOD. 

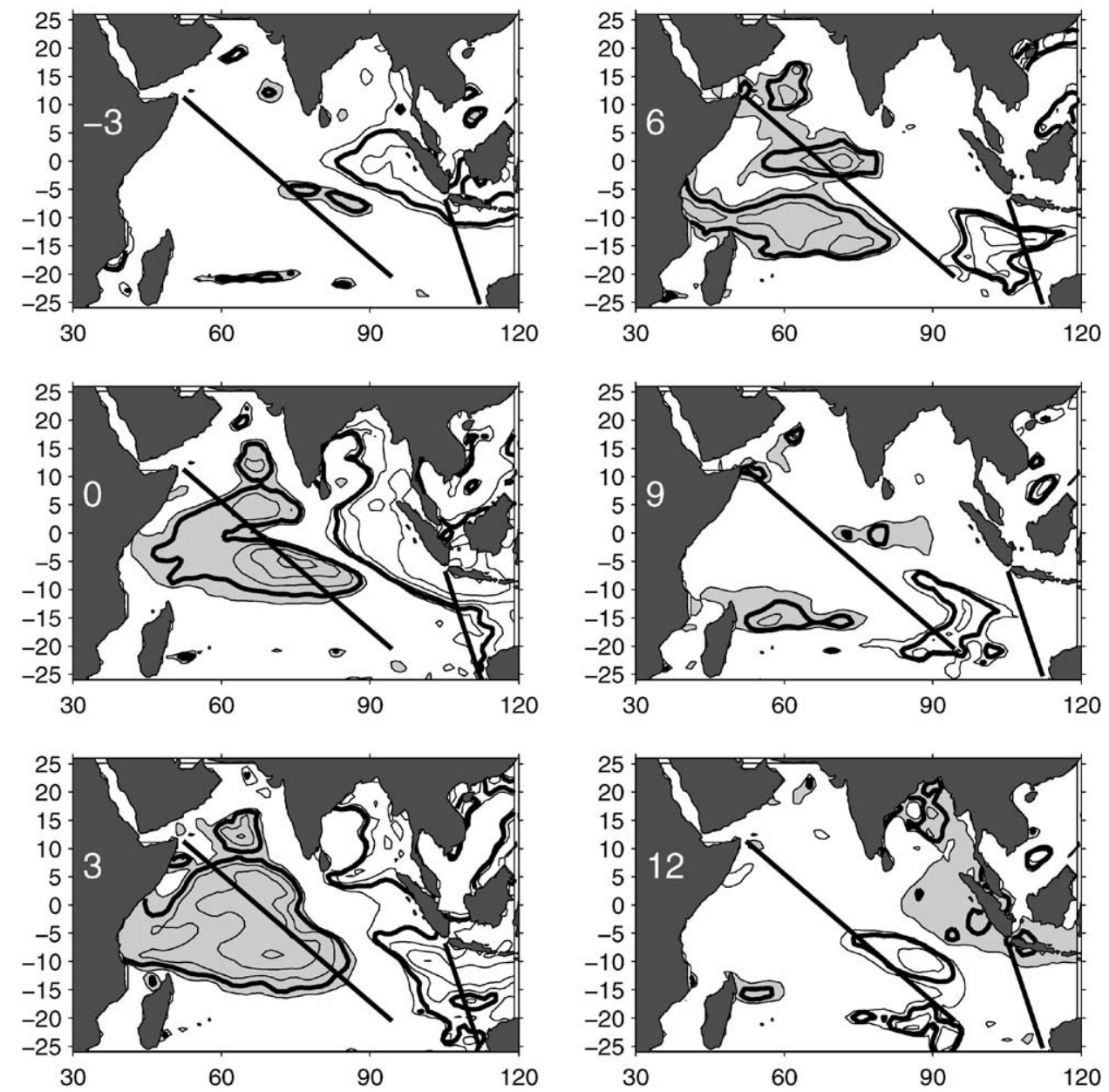

Fig. 14. Lag correlation between SLA and the tropical Indian Ocean wind index. The numbers in the African landmass denote the lagging time of SLA relative to the wind index. Shaded areas denote positive correlation and only correlations larger than 0.5 are contoured with an increment interval of 0.1 . The heavy contours are 0.6 . The locations of the XBT sections are denoted.

\section{The ENSO teleconnection into the Indian Ocean}

The analysis of XBT and SLA observations in Sections 5 and 6 lead us to believe that the subsurface evolution in the Indian Ocean is driven by Indian Ocean SST (particularly in the SumatraJava upwelling region) and regional ocean-atmosphere interaction, and to a less extent by the global ENSO teleconnection through the atmosphere. In this section, we will use a statistical analysis to identify the relative strength of regional and ENSO forcings on subsurface structure. As from the EOF and EEOF analyses, we use the equatorial wind index to represent the subsurface dynamics. We use inverted SOI for ENSO. Other ENSO indices give similar results. The SST difference in the Indian Ocean represents the contribution from tropical Indian Ocean instability.

The impact of ENSO on Indian Ocean SST has been documented by Enfield and Mestas-Nunez (1999) as a warming of the western Indian Ocean SST during El Niño that gradually spreads eastward as the episode matures. This is apparent in the 1997/98 ENSO in Fig. 2a. However, ENSO cannot explain some important features of Indian 

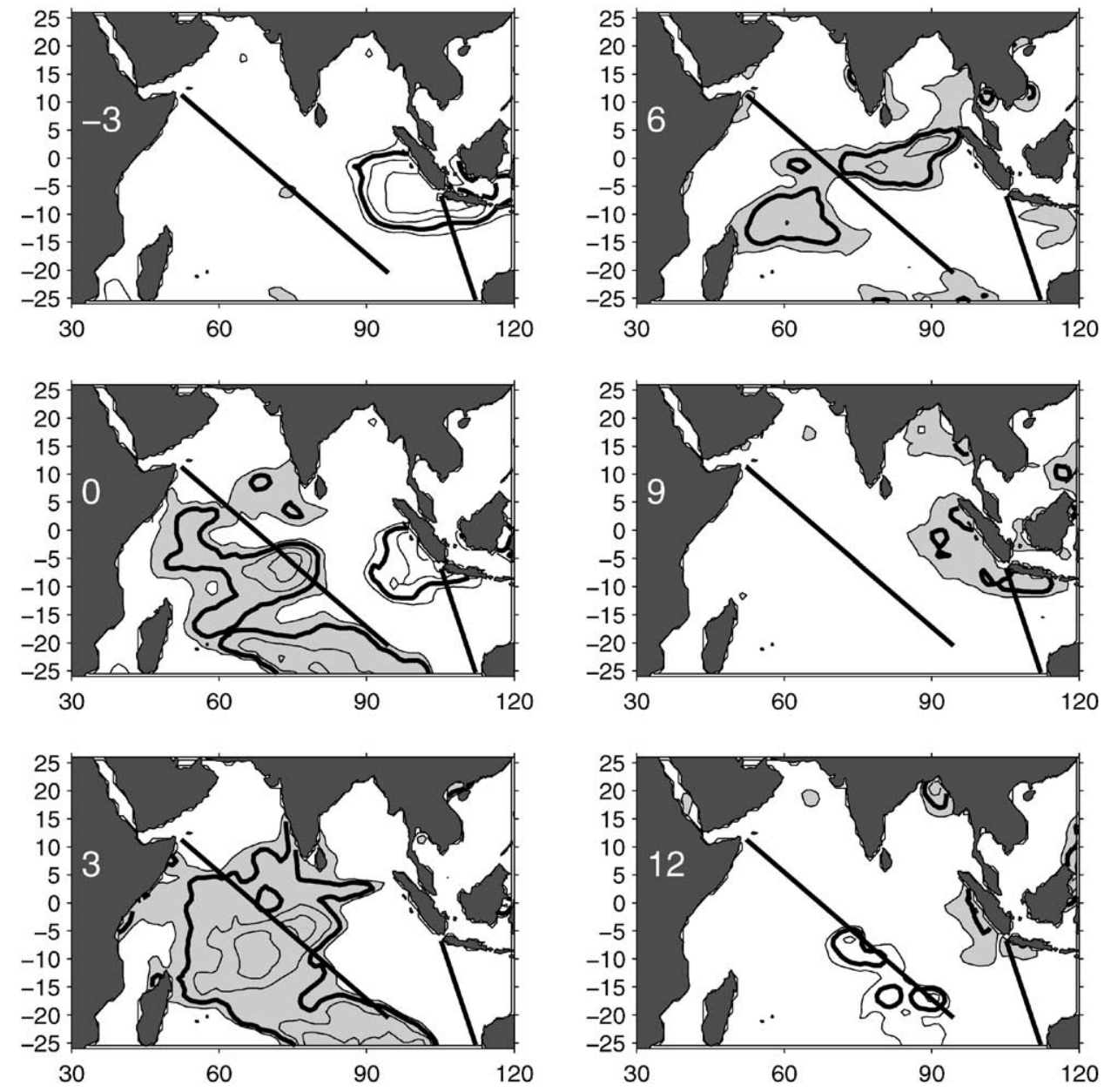

Fig. 15. Same as Fig. 14 except for correlation between SST and the wind index.

Ocean SST during the period of this study. In particular, during late 1983 to early 1986 the SOI is almost stationary (Fig. 2c) while SST in the east and west poles undergo considerable variation (Fig. 2a). Also SOI remains positive with little variation from 1990 to 1995 (Fig. 2c) while eastern Indian Ocean SST undergoes large positive and negative excursions. The western Indian Ocean cooling period during 1984/85 (Vinayachandran et al., 2001) is not described by SOI. Also the west and east SST anomalies are almost in phase during the 1986/87 El Niño, while they have different phase relationships during other time periods. The eastern and western SST variations that are not driven by ENSO are an important aspect of Indian
Ocean variability that manifests itself in the SST difference across the ocean and its impact on zonal wind.

The zero-lag correlations between ENSO (represented by inverted SOI), SST difference across the Indian Ocean and IOD thermal structure (represented by zonal wind index) are presented in Fig. 17. The correlation between inverted SOI and SST difference is 0.56 . The wind index correlation with the inverted SOI is 0.67. A referee asked for wind index correlations with other ENSO indices including Nino3.4 SST (170$\left.120^{\circ} \mathrm{W}, 5^{\circ} \mathrm{S}-5^{\circ} \mathrm{N}\right)$ and Multivariate ENSO Index (MEI; Wolter, 1987) which are 0.65 and 0.62 , respectively, confirming the correlation to inverted 

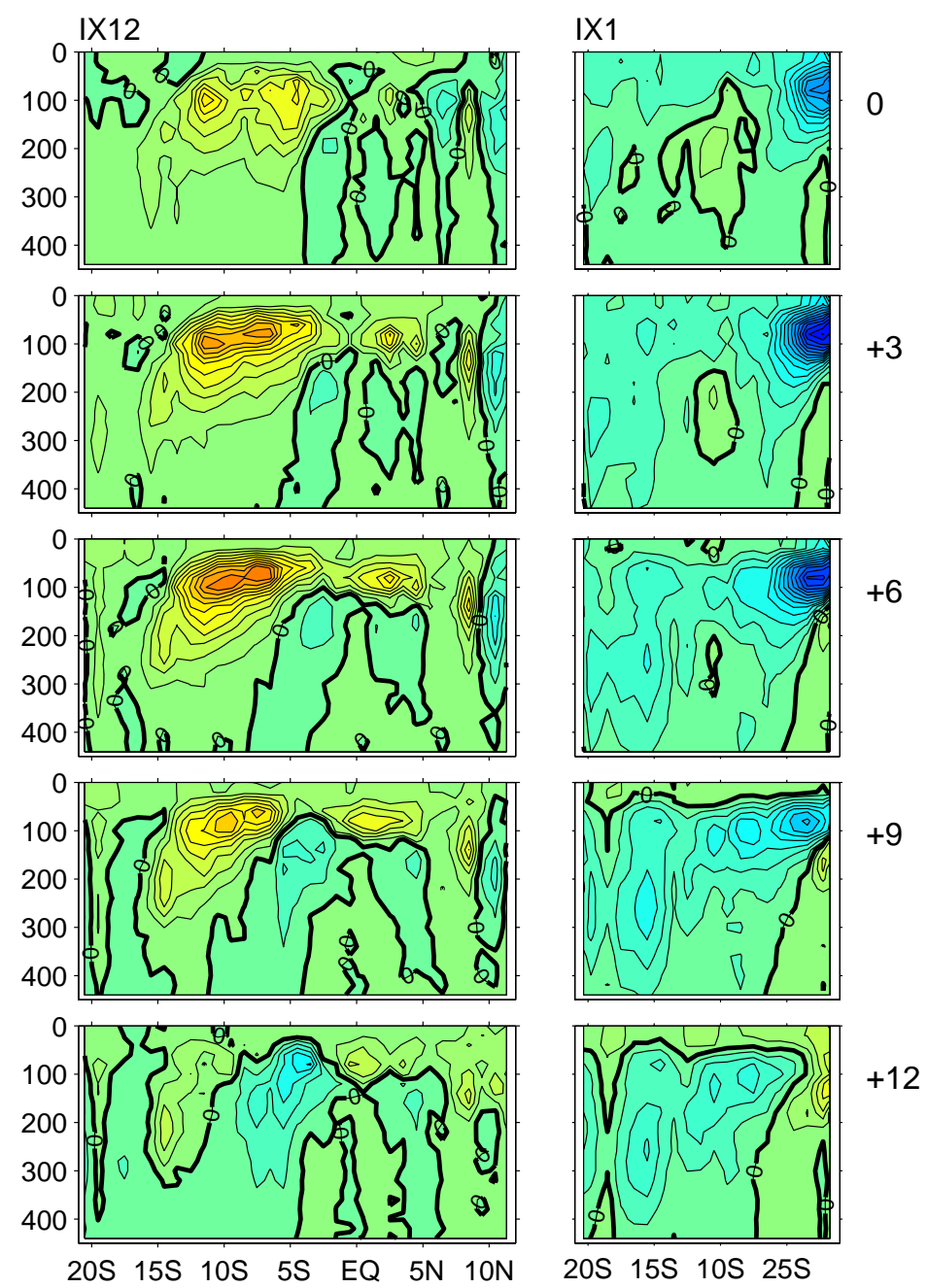

Fig. 16. Loading sequence of the XBT EEOF-2. The lags are every 3 months, as denoted to the right of the panels. The contour interval is $0.1^{\circ} \mathrm{C}$. Red area denotes positive anomaly and blue for negative anomaly. The zero contours are labelled.

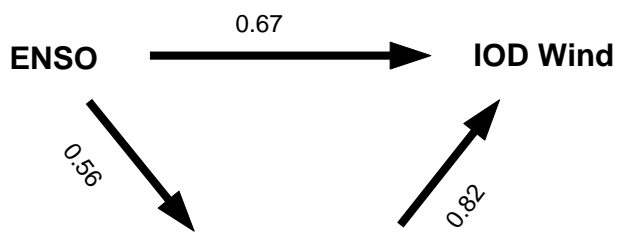

Indian Ocean SST

Fig. 17. A sketch that denotes the partial explanation relationship between SOI, SST difference in the tropical Indian Ocean, and the IOD wind index. The arrows denote influence and the numbers are correlation coefficients.
SOI. Both the SST difference and the wind index have dissimilarity with inverted SOI. Namely, while inverted SOI is always positive during the extended El Niño in 1991-1994 (Fig 2c), the wind index reverses its sign in 1992, and then becomes positive and is strongly amplified during 1994, following the SST difference. On the other hand, the wind index is highly correlated with the interannual SST difference across the tropical Indian Ocean, with a zero-lag correlation of 0.82 (Fig. 17) and a lag correlation of 0.86 (SST difference leading by 1 month) (Fig. 2b). Clearly, 
the correlation between the Indian Ocean SST difference and the IOD wind is higher than the correlation with inverted SOI. Note that the peak westward wind anomaly occurs in SeptemberNovember during an IOD event, lagging the peak SST difference by about 1 month. This lagging relationship may indicate the oceanic forcing on the atmosphere.

To compare the influences of ENSO and Indian Ocean SST on the wind index, we carry out multiple linear regression, partial correlation, and part correlation analyses (David Garson, North Carolina State University, online textbook on Quantitative Research in Public Administration; Hutcheson and Sofroniou, 1996). As in the above correlation analysis, we use inverted SOI to represent ENSO teleconnection, while the SST difference to represent the local air-sea instability, and the subsurface variation is indexed by the zonal equatorial wind.

The multiple linear regression can be expressed as: $\tau_{\text {west }}=\beta_{1} *(-\mathrm{SOI})+\beta_{2} * \Delta \mathrm{SST}$, where $\tau_{\text {west }}$ is the wind index, and the regression coefficients $\beta_{1}$ and $\beta_{2}$ are called $\beta$-coefficients when all indices are normalized. The linear regression explains $74 \%$ of the wind index variance during 1981-1999. The $\beta$ coefficient for the SST difference is 0.66 , while that for inverted SOI is only 0.30 (Table 1), indicating that the tropical Indian Ocean SST difference has more than twice the inverted SOI influence on the wind index. Note that the ratio between the $\beta$ coefficients is the ratio of predictive importance of the independent variables.

In order to delineate the causal relationship between ENSO, SST, and wind, we calculate the partial correlation between the inverted SOI and wind, and between the SST difference and the wind (Table 1). The partial correlation between SOI and the wind index is 0.43 by removing the influence of the Indian Ocean SST, while the partial correlation between the Indian Ocean SST and wind index is 0.73 by removing the SOI influence (Table 1). Because the partial correlation between the inverted SOI and wind is smaller than the direct correlations (0.67), the relationship between ENSO and the wind index is partial explanation through SST as depicted in Fig. 17. That is, the SST difference is an intervening variable between the inverted SOI and the wind index, and part of the direct correlation between the inverted SOI and wind is due to the fact that they are both correlated with the SST difference.

Part correlation, also called semi-partial correlation, is the same as partial correlation except that the common variance in the wind index is not removed, so that the part correlation squared represents the total wind variance can be independently explained by an independent variable (Table 1). That is, from the multiple linear regression we know that the inverted SOI and SST difference explain totally $74 \%$ of the wind index variance. By removing the inverted SOI from the linear regression, only $6 \%$ less variance is explained by the SST difference alone, while by removing the SST difference from the linear regression, $29 \%$ less variance is explained. Thus, inverted SOI is has a much smaller independent impact on the wind index.

Table 1

Relationships between the wind index and inverted SOI/Indian Ocean SST difference

\begin{tabular}{lllll}
\hline & $\beta$-Coefficient & Partial correlation & Part correlation (semi-partial) & Part correlation squared (\%) \\
\hline Inverted SOI & 0.30 & 0.43 & 0.25 & 6 \\
SST difference & 0.66 & 0.73 & 0.54 & 29 \\
\hline
\end{tabular}

Note: $\beta$-Coefficients are linear regression coefficients for the wind index using normalized data, representing the predictive powers of the independent variables, SOI and SST difference. Partial correlation is the correlation between the wind index and inverted SOI (SST difference) after removing the common variance with SST difference (inverted SOI) from both inverted SOI (SST difference) and the wind index. Part correlation, also called semi-partial correlation, is the correlation with the wind index when the common variance is only removed from inverted SOI (SST difference). 


\section{Summary and discussion}

An Indian Ocean Dipole (IOD) event starts with anomalous SST cooling along the Sumatra-Java coast in the eastern Indian Ocean during MayJune. The normal equatorial westerly winds during June-August weaken and reverse direction. And an IOD event peaks near September-October, with warmer than usual SST over large parts of the western basin (Saji et al., 1999). However, because there is non-negligible correlation between ENSO and IOD indices (Nicholls and Drosdowsky, 2001), there is a vigorous scientific debate over whether or not IOD is in any way independent of ENSO. The present study provides a consistent picture of the subsurface ocean dynamics in IOD evolution and potential role of subsurface temperature to influence SST.

From both EOF and EEOF analyses of the altimeter and XBT subsurface temperature data, an IOD event is initiated by an anomalous upwelling along the Sumatra-Java coast at the start of the normal upwelling season in May-June. This enhances cooling of sea-surface temperature (SST) in the eastern Indian Ocean, which couples with a westward wind anomaly along the equator and drives rapid growth of IOD through further upwelling. The wind anomaly and associated Ekman pumping generate off-equatorial Rossby waves that travel westward, deepen the thermocline, and warm SST in the western Indian Ocean, causing the peak of an IOD event a few months after it begins. The decay of an IOD event is characterized by a slow eastward propagation of warm anomaly along the equator, with warm SST leading deepened thermocline depth. The deepened thermocline arrives at the eastern boundary and reduces the rate of cooling during the next upwelling season. This causes a positive SST anomaly in the eastern Indian Ocean in the following year of an IOD event. The evolution of the event during two upwelling seasons involves the SST, wind, and subsurface temperature. There are upward propagations of temperature anomaly from subsurface to surface layer in the XBT EEOF analysis, which implies the potential role of ocean dynamics on the SST. The upper-ocean evolution in the tropical Indian Ocean is unique to IOD (that is, similar upper-ocean evolution does not occur during the 1986/87 El Niño), and tends to have a 2-year time-scale. The 2-year time-scale is likely determined by the internal coupled dynamics of the Indian Ocean.

The SST difference across the tropical Indian Ocean leads the westward wind stress anomaly along the equator by 1 month with a correlation of 0.86 , although the SST anomalies at the western and eastern Indian Ocean have different amplitudes during different IOD events. The westward wind anomaly can be used to represent the interannual subsurface variability of the Indian Ocean. The correlation between the wind index and Southern Oscillation Index (SOI) is 0.67 , less than the correlation between the wind index and the SST difference, and SOI does not capture some features shown in the wind index. The partial correlation between SOI and wind index is 0.43 , indicating that the relationships between the SOI, SST, and wind index are partial explanation. From linear regression, ENSO likely has less influence on the wind index than the SST difference across the tropical Indian Ocean $(0.30$ versus 0.66 in terms of $\beta$-coefficients). Thus, the subsurface evolution in the tropical Indian Ocean (indexed by the zonal equatorial wind) is strongly affected by Indian Ocean SST zonal gradient, and to a less extent by El Niño Southern Oscillation.

The role of subsurface ocean dynamics in IOD is described in this study primarily on the basis of two, possibly isolated events in 1994/95 and 1997/ 98. These events seem to grow through positive feedback involving easterly wind anomaly, large scale upwelling off Java and Sumatra and cooling of SST, which increases the wind anomaly. Despite its potential role during the growth of these events, it is not clear that ocean atmosphere coupling in the Indian Ocean is as self-contained and continually sustained as the Pacific. Nevertheless, the evolution of these events over a period of two upwelling seasons seems to be controlled by forced planetary wave propagation that amplified during the episode. The interannual amplification is closely related to Monsoon driven wind fields (Masumoto and Meyers, 1998) and may be a mechanism that links ENSO and Monsoon variability in the Indian Ocean. The observed 
behavior of the tropical Indian Ocean and the role of internal ocean dynamics suggest a coupled ocean/atmosphere instability in the Indian Ocean, which may be initiated by ENSO or other anomalies during the early Sumatra-Java upwelling season; however, proof of its existence will require further research, in particular modelling and model-validation that accurately simulates the internal Indian Ocean structure observed in this study.

There are remaining issues to extend this research. How do the warm SST anomaly and deepened thermocline in the western Indian Ocean translate into the equatorial coupled mode? What is the mechanism for the coupled mode? How do the off-equatorial Rossby waves and the equatorial coupled waves affect the mixed layer heat budget? What is the threshold to trigger the tropical Indian Ocean instability? Due to the close linkage between the Indian Ocean and Pacific, a better understanding of IOD and its interaction with ENSO will enhance our ability to understand and predict regional climate variability.

\section{Acknowledgements}

This work was partly supported by the Strategic Research Fund for Marine Environment, CSIRO Marine Research. We thank Lidia Pigot, Neil Whilte, and Jim Mansbridge for processing and archiving the data sets used in the study. Toshio Yamagata and Saji Hameed shared their manuscripts with us before publication and contributed to our interpretation of the observations. We thank Fritz Schott, the Guest Editor of Deep-Sea Research, for his encouragements. We also thank Tara Ansell, David Griffin, and two anonymous reviewers for valuable comments.

\section{References}

Behera, S.K., Krishnan, S., Yamagata, T., 1999. Unusual ocean-atmosphere conditions in the tropical Indian Ocean during 1994. Geophysical Research Letters 26, 3001-3004.

Chambers, D.P., Tapley, B.D., Stewart, R.H., 1999. Anomalous warming in the Indian Ocean coincident with El Niño. Journal of Geophysical Research 104, 3035-3047.
Clarke, A.J., Liu, X., 1993. Observations and dynamics of semiannual and annual sea levels near the eastern equatorial Indian Ocean boundary. Journal of Physical Oceanography 23, 386-399.

Clarke, A.J., Liu, X., 1994. Interannual sea level in the northern and eastern Indian Ocean. Journal of Physical Oceanography $24,1224-1235$.

Donguy, J.R., Meyers, G., 1995. Observations of geostrophic transport variability in the western tropical Indian Ocean. Deep-Sea Research I 42, 1007-1028.

Enfield, D.B., Mestas-Nunez, A.M., 1999. Multiscale variabilities in global sea surface temperatures and their relationships with tropospheric climate patterns. Journal of Climate 12, 2719-2733.

Feng, M., Meyers, G., 2001. Interannual upper ocean variability in the tropical Indian Ocean from extended EOF analysis. BMRC Research Report No. 84, Bureau of Meteorology Research Centre, Melbourne, Vic., Australia, pp. $17-20$.

Feng, M., Meyers, G., Wijffels, S., 2001. Interannual upper ocean variability in the tropical Indian Ocean. Geophysical Research Letters 28 (21), 4151-4154.

Hutcheson, G., Sofroniou, N., 1996. The Multivariate Social Scientist: Introductory Statistics Using Generalized Linear Models. Sage, Thousand Oaks, CA.

Kalnay, E., et al., 1996. The NCEP/NCAR 40-year reanalysis project. Bulletin of American Meteorological Society 77, 437-471.

Lau, K.-M., Chan, P., 1985. Aspects of the 40-50 day oscillation during the northern winter as inferred from outgoing longwave radiation. Monthly Weather Review 113, 1889-1909.

Lau, K.-M., Wu, H.-T., 1999. Assessment of the impacts of the 1997-98 El Niño on the Asian-Australia Monsoon. Geophysical Research Letters 26, 1747-1750.

Le Traon, P.Y., Nadal, F., Ducet, N., 1998. An improved mapping method of multi-satellite altimeter data. Journal of Atmospheric and Oceanic Technology 25, 522-534.

Levitus, S., Boyer, T.P., 1994. World Ocean Atlas 1994 Vol. 4: Temperature. NOAA Atlas NESDIS 4, US Department of Commerce, Washington, DC, USA, 117pp.

Masumoto, Y., Meyers, G., 1998. Forced Rossby waves in the southern tropical Indian Ocean. Journal of Geophysical Research 103, 27589-27602.

Meehl, G.A., 1993. A coupled air-sea biennial mechanism in the tropical Indian and pacific regions: role of the ocean. Journal of Climate 6, 31-41.

Meehl, G.A., Arblaster, J.M., 2002. The tropospheric biennial oscillation and Asian-Australian Monsoon rainfall. Journal of Climate 15, 722-744.

Meyers, G., 1996. Variation of Indonesian throughflow and the El Niño-Southern Oscillation. Journal of Geophysical Research 101, 12255-12563.

Meyers, G., Pigot, L., 1999. Analysis of frequently repeated XBT lines in the Indian Ocean. CSIRO Marine Laboratories Report 238. CSIRO Marine Research, Hobart, Australia, 43pp. 
Nicholls, N., Drosdowsky, W., 2001. Is there an equatorial Indian Ocean SST dipole, independent of the El NiñoSouthern Oscillation? American Meteorological Society 81st Annual Meeting, Albuquerque, NM, 14-19 January 2001.

Perigaud, C., Delecluse, P., 1993. Interannual sea level variations in the tropical Indian Ocean from Geosat and shallow water simulations. Journal of Physical Oceanography 23, 1916-1934.

Rao, A.S., Behera, S.K., Masumoto, Y., Yamagata, T., 2002. Interannual variability in the subsurface Indian Ocean with special emphasis on the Indian Ocean Dipole. Deep-Sea Research II 49, 1549-1572.

Reynolds, R.W., Smith, T.M., 1994. Improved global sea surface temperature analyses. Journal of Climate 7, 929-948.

Saji, N.H., Goswami, B.N., Vinayachandran, P.N., Yamagata, T., 1999. A dipole mode in the tropical Indian Ocean. Nature 401, 361-363.

Schott, F.A., McCreary, J.P., 2001. The monsoon circulation of the Indian Ocean. Progress in Oceanography 51, 1-123.

Schott, F., Fischer, J., Garternicht, U., Quadfasel, D., 1997. Summer monsoon response of the northern Somlai Current, 1995. Geophysical Research Letters 24, 2565-2568.
Vinayachandran, P.N., Saji, N.H., Yamagata, T., 1999. Response of the equatorial Indian Ocean to an unusual wind event during 1994. Geophysical Research Letters 26, 1613-1616.

Vinayachandran, P.N., Iizuka, S., Yamagata, T., 2001. Indian Ocean Dipole mode events in an ocean general circulation model. Deep-Sea Research, in press.

Webster, P.J., Moore, A.M., Loschnigg, J.P., Leben, R.R., 1999. Coupled ocean-atmosphere dynamics in the Indian Ocean during 1997-98. Nature 401, 356-360.

Wolter, K., 1987. The Southern Oscillation in surface circulation and climate over the tropical Atlantic, Eastern Pacific, and Indian Oceans as captured by cluster analysis. Journal of Climate and Applied Meteorology 26, $540-558$.

Xie, S.-P., Annamalai, H., Schott, F.A., McCreary, J.P., 2002. Structure and mechanisms of South Indian Ocean climate variability. Journal of Climate 15, 864-878.

Yu, L., Rienecker, M., 1999. Mechanisms for the Indian Ocean warming during the 1997-98 El Niño. Geophysical Research Letters 26, 735-738. 